\title{
Feminist Postdigital Inquiry in the Ruins of Pandemic Universities
}

\author{
Zoë Hurley ${ }^{1}\left[\right.$. Khadija Al-Ali ${ }^{2}$
}

Accepted: 6 August 2021 / Published online: 3 September 2021

(c) The Author(s), under exclusive licence to Springer Nature Switzerland AG 2021

\begin{abstract}
During Covid-19, higher education made an unprecedented entry into the domestic sphere. However, not all students welcomed the emergency delivery of online courses. Consequently, some learners have been developing resistant practices to technology-driven learning, including being on mute and turning off cameras, but these silences, gaps and evasions are difficult to grasp through normative perspectives. Meanwhile, big tech continues to profit significantly from its encroachment on pedagogy. Conversely, we need alternate conceptions of learners' varying responses to technologies. To develop a novel perspective, the study considers the Middle East's traditional mashrabiyya windows, which are carved through an elaborate wooden latticework screen of geometric patterns and designed to deflect rather than let in the light. This mashrabiyya structure is applied as a theoretical metaphor to consider Arab women learners' technological veiled affordances of filters, avatars and not replying. The mashrabiyya feminist postdigital framework develops unique inquiry into learners' subtle practices; the authors' self-reflexivity; and analysis of a (silent) email exchange and a Twitter avatar. Theorising suggests silences, invisibilities and disconnection are not necessarily a deficit but refractive responses enabling students and educators to stay below the radar.
\end{abstract}

Keywords Online learning $\cdot$ Surveillance $\cdot$ Silences $\cdot$ Mashrabiyya feminist postdigital inquiry $\cdot$ Refractive $\cdot$ Invisibilities $\cdot$ Below the radar

Zoë Hurley

Zoe.hurley@zu.ac.ae

Khadija Al-Ali

ky.alali@paaet.edu.kw

1 Zayed University, Dubai, United Arab Emirates

2 Public Authority for Applied Education and Training, Kuwait City, Kuwait 


\section{Introduction}

More than a year-and-a-half into the Covid-19 pandemic and we are atomised, uncertain but ever hopeful, while clinging to the cruel optimism that life has to get better. The health emergency has been called the 'new normal' and it is seemingly here to stay, but there is nothing 'normal' or standard about different countries' reactions to the pandemic. There is not even something necessarily 'new' about postdigital tethering to screens. Meanwhile, big tech continues to profit from the commercialisation of education. For instance, in every minute of the first 3 months of 2021, Apple, Google owner Alphabet, Amazon, Facebook and Microsoft sold products and services worth about $\$ 2.5 \mathrm{~m}(£ 1.8 \mathrm{~m})$ combined. Profits before tax for the period came in at $\$ 88 \mathrm{bn}-$ more than $\$ 1 \mathrm{bn}$ of profit for every working day (Jolly 2021). While algorithmic data tallies up the numbers of suffering, redundancies, deaths and profit, the study asks: (1) How can we conceptualise Arab women's technological practices in the postdigital condition? (2) How have Arab women responded to the rapid technological shift to online delivery of education?

These are important issues that contest commercialised claims of big tech. We thus develop unique inquiry into the subtle practices of the pandemic university. The theoretical approach advances through the sensibility of the Middle East's traditional mashrabiyya windows. Mashrabiyya frames are carved through an elaborate wooden latticework screen of geometric patterns and designed to deflect rather than let in the light. This mashrabiyya structure is applied as a metaphor to consider learners' varying technological practices. Arab women learners, at universities in Kuwait and the United Arab Emirates (UAE), are taken as a case to illustrate postdigital practices within 'scopic regimes' (Mirzoeff 2006). The notion of scopic regimes is central to the inquiry and we explain this concept next.

The term 'visual regime', coined by the French film theorist Christian Metz (1975), distinguished the acts of looking in the cinema from the theatre. Metz explained that 'what defines the cinematic scopic regime is not so much the distance kept ... as the absence of the object seen' (Metz 1982: 61). The notion of visual or scopic regimes is pivotal to this study because it highlights the extent to which, what and how we see, or do not see, are discursive and mediated via technologies, ideologies and cultural practices (Mirzoeff 2006). Within a particular culture or historical regime of seeing, visuality is structured via complex visual codes (Jay 1988). The study's explicit theoretical perspective is informed by a sense of scopic regimes which accent technological learning practices. This is crucial because we are acutely aware that women face particular gendered challenges that represent invisibilities, silences and alternate modes of communication (Hurley 2021a; Ali-Ali 2021). To consider the question of Arab women students' postdigital practices, the following folds of inquiry occur.

- First, we discuss literature relevant to Arab women students, their Middle Eastern context and the global downturn of pandemic higher education.

- Second, we develop the mashrabiyya postdigital feminist framework, concerned with theorising Arab women learners' postdigital practices. This develops self-reflexivity about our own postdigital identities as women academics in the Middle East and the interpretive narratives of research. 
- Third, the mashrabiyya feminist postdigital framework is applied for interpretive inquiry into an email exchange and a Twitter avatar.

- Fourth, discussion of the findings helps to address the study's research questions, which consider Arab women students' postdigital practices within the pandemic university.

To advance the inquiry, we start with the literature.

\section{Literature Review: Pandemic Learning in the Ruins}

The literature reviewed was thematically selected from Google Scholar and academic data bases. Themes of inquiry include Covid-19; feminism and the Middle East; visual practices and technology-driven pedagogies. We begin with a reflection on some of the momentous impacts of Covid-19.

\section{Covid-19}

The novelist Roy (2020) explains that the coronavirus pandemic has involved a pivot of our values. She says the pandemic is:

a portal, a gateway between one world and the next. We can choose to walk through it, dragging the carcasses of our prejudice and hatred, our avarice, our data banks and dead ideas, our dead rivers and smoky skies behind us. Or we can walk through lightly, with little luggage, ready to imagine another world. And ready to fight for it. (Roy 2020)

Roy's powerful words evoke the cataclysmic shift of Covid-19. They beg the question of how women can be expected to go into the Covid portal and 'walk through lightly' while presumably carrying children, elderly parents, financial debts and the electronic tentacles of email, Zoom and social media? However, Roy does not advance a focus on Arab women students or how they might get ready for the 'fight', while the pandemic has turned the clock back on gender equality by several decades (Hurley 2020; Johnston 2021)? These issues align with the research questions of the inquiry which explore conceptualisations of Arab women's postdigital practices and their responses to online education within the domestic sphere. To consider further, how Arab women learners have been affected by Covid-19, next we discuss the Middle East North African (MENA) context.

\section{MENA}

MENA is a vast and diverse region, made up of differing languages, dialects, races, cultural and gender practices that are often grouped together for theoretical purposes. MENA countries are listed as including Syria, Libya, Iraq, Palestine, Jordan, 
Bahrain, United Arab Emirates (UAE), Kuwait, Kingdom of Saudi Arabia (KSA), Iraq, Oman, Qatar, Yemen, Egypt, Malta, Morocco, Tunisia, Algeria, Somalia, Sudan, Algeria and Djibouti. Wider regions of Pakistan and Afghanistan are sometimes included (Abed and Davoodi 2003). Islam is the dominant religion and Arabic is the main language but there are significant minority groups, other religions and linguistic diversities (Abed and Davoodi 2003). Not surprisingly, the varying experiences of Arab women during Covid-19 vary significantly across MENA.

At the beginning of the pandemic, some universities in the MENA region faced serious challenges pivoting to remote teaching, learning and research. In Sudan, North Africa, for example, only $0.3 \%$ of the population have been vaccinated (Sawahel 2021). Vaccines that were donated to South Sudan are close to their expiry dates while health workers not only lack the infrastructure to administer them but are also skeptical about their safety (Mwai 2021). Even when more vaccines become available, teachers in Sudan are second in line following, essential workers, the elderly and vulnerable groups. As a result of the obstacles delaying administration of vaccines, some Sudanese universities, including the Ahfad University for Women, have announced the suspension of all academic activities, including classes and exams for undergraduate and postgraduate students (Sawahel 2021).

Meanwhile, in Palestine, all seven universities in Gaza have been destroyed due to bombing while online education activities, including lectures, assignments and exams, have been suspended (El-Tohamy 2021). In the second quarter of 2020, unemployment in Saudi Arabia hit a record high of over 15\%, with young Saudis making up nearly two-thirds of all unemployed. Similarly, $41 \%$ of young people in the UAE say that finding a new job is more difficult now than before the pandemic. Today's students also often feel that the tuition bills they pay are out of all proportion to the educational experience they are getting during the pandemic (Anderson 2020). Simultaneously, most universities in the Gulf remain empty, apart from the cleaners and security guards, yet the deserted buildings pump out air conditioningday and night—due to the blistering heat and need to keep computational systems cool. However, this has specifically gendered impacts, some of which we discuss next.

\section{Gendered Impacts}

Gendered impacts of the pandemic continue to spiral. Exploring women's learning in Middle Eastern contexts from a feminist perspective is an important endeavour, particularly in view of Western stereotypes surrounding Muslim women as passive and needing to be unveiled, while Arab women do not necessarily view themselves in these terms (Ahmed 2011; Abu-Lughod 2005). Despite evident diversity of Arab women's lives, stereotyping of Muslim women as passive victims in the Western media has been discussed by Middle Eastern scholars for at least 40 years (Abu-Lughod 2005; Mohanty 1988). There is also a substantial body of literature that critiques liberal feminism's misunderstandings of Arab women's subjectivities (Ahmed 2011). Furthermore, Arab feminists like Nawal El Saadawi (1983) have pointed out that it is not only Arab women who are oppressed by patriarchy. 
Theorising Arab women's higher education beyond stereotypes needs to depart from ethnocentric perspectives that the West is the locus of knowledge, experience and emancipation (Hurley 2019a, b, 2021b). Arab scholarship has been instrumental in shaping many of the ideas that we may associate with being Western and vice versa (Watt 1994). Conversely, theoretical decolonialisation does not stem from cultural crossovers entirely but also via incongruities of epistemologies and positionalities (Tuck and Yang 2012). We thus recognise that Arab women students' postdigital practices could occur in tandem and/or independently from Western pedagogic traditions and conceptions. These involve visual practices and technology-driven pedagogies which we discuss next.

\section{Visual Practices and Technology-Driven Pedagogies}

In the Gulf Arab context, where both authors of this article are located, the drive to become knowledge economies occurs as an effort to capitalise upon knowledge (Lightfoot 2016). However, in the Gulf, like elsewhere, neoliberalism manifests as a series of imaginaries that vary according to gender (Brown 2015). Furthermore, appropriation of neoliberal discourses is not uniformly available for all subjects since they occur in gendered, classed and racialised terms (Grewal and Kaplan 2006). Despite the varying experiences of learning and the range of impacts of the pandemic, in certain respects, it is business as usual in the neoliberal university (Hurley 2020). However, as mentioned, many of MENA's campuses are now devoid of people. Computers, surveillance cameras and machines outnumber embodied students. Technological determinist rhetoric remains enthusiastic while naïve in its broad-brush statements about pedagogy (Hurley 2021a). Online solutionism and tech-driven research into learning are increasingly funded by big tech, who invest in the acceleration of marketisation, privatisation and commercialisation (Education International 2021).

Hayes (2021) describes this as the McDonaldisation of learning that has insidiously seeped into our language, logic and identities. McDonaldisation is the process by which the Fordist principles of the fast-food industry are infiltrating the practices of society. However, the McDonaldisation of education impacts in gendered ways but there is a gap in knowledge in respect to these practices. In this article, we therefore explore how mashrabiyya feminist postdigital inquiry offers fine-grained insights into Arab women students' postdigital practices.

In the postdigital condition, subtle interpretations are important considering that the nuances of varying scopic regimes can be difficult to grasp. Subtleties include, differing modes of gaze, variations of the visual subject and hybrid mediations of the synthetic image, but pixels and code conjuring images within the computational data systems are considered black-boxed, discreet and difficult to understand. Consequently, art historian Belting (2011a) suggests that visual perspectives of seeing, and not seeing, have lost their physical embodiments and connections that windows, paintings or photographs may have afforded. Furthermore, when Western scopic regimes are positioned as universal, this brackets-off other cultural gendered visual histories that impact upon the postdigital. 
Nevertheless, at deeper levels, there are significant sociocultural and historical differences between Arab and Western scopic regimes of the gaze. While the visual drive is evident in all humans, albeit at literal or conceptual levels, societies and cultures do not make the same use of the gaze. Belting (2011a) says that mirrors and windows denote general attitudes that determine the visual realm but also have entirely different meanings in individual cultures. Attitudes towards the gaze are reflected in architecture, the domestic sphere, norms for showing and perceiving self. To illustrate, we can consider further the traditional Arab mashrabiyya windows which inform the theoretical framework of the study.

\section{Oblique Gaze: Mashrabiyya Feminist Postdigital Framework}

Mashrabiyya windows are carved through an elaborate wooden latticework screen of geometric patterns and accented to distort the light (Fig. 1).

Belting (2011b) suggests mashrabiyya windows, as illustrated in Fig. 1, accent differences between the Western and Arab gaze. He says, 'mashrabiyya tames the gaze and purifies it of all sensuous external images through its strict geometry of interior light' (Belting 2011b: 260). In view of the hot summer temperatures of the Arab context, the mashrabiyya window was certainly pragmatic. Each mashrabiyya screen is unique and their geometrics continue to influence contemporary Arabian architecture, for example the Louvre, Abu Dhabi. The UAE's Louvre-not to be confused with Paris's original gallery_opened in Abu Dhabi in 2017 (Taylor 2017). Pritzker Prize winning architect Jean Nouvel's design takes inspiration from the concept of a medina, the ancient quarter of many Arab cities. Nouvel constructed a 591-foot silvery metal dome comprising of 7850 stars in complex mashrabiyya geometric patterns (Suri 2017). Also designed according to mashrabiyya principles is Qatar's Doha Tower known as the Burj Doha (O'Keefe 2014).

Belting (2011b) explains that the mashrabiyya structure continues to be significant in the Arab context, particularly because it differs to Western traditions and

Fig. 1 'Arabian window'. (C) 2021. Freeimages

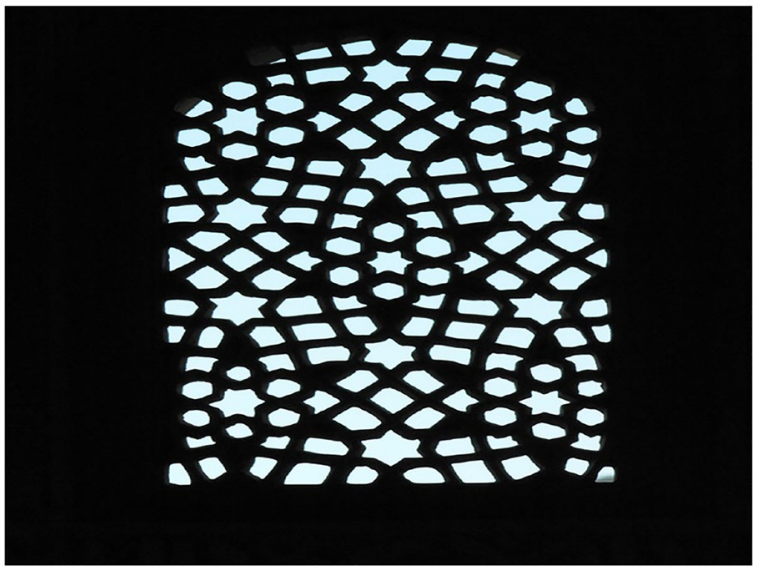


conceptions of windows, accented to open, and let in the light. While not representing a simple binary, varying window designs indicate differing worldviews assigning different roles to the observing subject. In the case of an open window world, the subject is active in his or her gaze but can also be observed. Alternatively, mashrabiyya geometry mediates the gaze through cosmic patterns of light, concealing the observer and screening them off within the private realm (Belting 2011b).

Pfohl et al. (2021) image/text article develops a postdigital 'pedagogy of pedagogy that resists unilateral prescriptions and is instead anchored around openness, expansion and individualisation'. Pfohl and the collective of imagemakers and authors explore how learners have more in common with works of art than numbers while asserting that aesthetics opens theorising of learning and teaching. Pfohl et al. (2021) visual article develops the citing of images as central to postdigital educational theorising. Critical pedagogist Giroux (2004) also has a strong belief in visual culture's potential to rupture traditional education's orthodoxies and rules. Furthermore, educational theorist and activist William Ayers (2016) suggests that the arts help us to see anew. This visual theorising is therefore developed in this inquiry.

\section{Oblique Framings}

The theoretical framework of our study is informed by oblique mashrabiyya insights. This perspective could help to reorientate and see anew Arab women learners' refractive or resistant, veiled and under the radar responses (Abidin 2021). As the authors of this study, working at universities in the United Arab Emirates and Kuwait, we are currently working within mashrabiyya practices and draw on mashrabiyya structures as (in)tangible ways of being and knowing.

While concerned with modern technologies and feminist futures, mashrabiyya feminist postdigital inquiry recognises that human technological tools have an ancient history and are underpinned by cultural scopic regimes (Mirzoeff 2006). Developing mashrabiyya feminist postdigital theoretical tools, to explore alternate scopic regimes, are required but do not merely involve side-stepping androcentric and ethnocentric philosophy. Developing mashrabiyya feminist postdigital reflexivity thus requires critically reorientating knowledge and dissemination within which it participates.

The search for new conceptual tools has a long tradition within feminist philosophy and involves salving backgrounded feminist pasts. For example, feminist pragmatist philosophy recognises proto-feminists of the early twentieth century, including American social reformer Jane Addams (1860-1935) and the mother of black feminism-Anna Julia Haywood Cooper (1858-1964). Feminist salvaging also acknowledges pragmatist feminists' vital contributions in the absence of critical language and conceptual apparatus to mitigate patriarchy and its suffering (Seigfried 1996). Conversely, androcentrism, and its racist, heteronormative and ableist fellowships, endure within the academy and beyond. Black lesbian feminist Lorde (1984: 15) suggests this is inevitable since the 'master's tools will never dismantle the master's house'. 
False binaries and hidden hierarchies haunt the analytic category of 'woman' in ways that prevent more reflexive, diverse and intersectional range of female experiences from being recognized (D'Ignazio and Klein 2020). Simultaneously, Western philosophical lenses that develop our understandings of gender, what it means to be male, female and indeed human, have been filtered through the androcentric and ethnocentric institutions within which they are entrenched. Lorde (1984) says that the differences between women cannot merely be acknowledged or tolerated but should spark dialectics, new ways of thinking and theorising. Moreover, black feminist and critical pedagogist, hooks (1994: 17), says, we might come to know differently, '... in fragments...we may learn from spaces of silence'. Parpart (2013) also discusses the politics of women's silence and suggests it can be an empowering strategy for dealing with difficult situations.

The above scholarship indicates that Arab women's experiences of patriarchy are seeped within the contexts in which they wade. Arab women's resistance also has a history that both pre-dates and continues with Islam (Al-Fassi 2007). What might loosely be described as the Arab women's liberation movement has been influenced by the feminist activisms of women in Egypt and the Levant (historic areas of Lebanon, Jordan, Palestine and Syria) and was a consequence of the increase in girls' education in the twentieth century. (In)visible feminisms and moves for women's liberation, through individual and organisational activities, began to develop in Egypt with the formation of the Egyptian Feminist Union in 1923 (Tijani 2009). Similar activities began to take place in a few of the Gulf states in the 1960s-1970s. Badran and Cooke (2004) describe a nexus between Arab women's activism, creative writing and women's magazines in the late nineteenth and twentieth centuries. This indicates the heterogeneity of Arab women's activism but also that Arab women have a substantial history of resistance, struggle and defining emancipation in their own terms.

Women in contemporary patriarchal Muslim societies reconcile contradictory, hybrid identities and transnational shifting lifestyles while by no means being entirely passive or victims (Abu-Lughod 2005). Beyond (and within) Western contexts, there are numerous examples of media conscious, economically empowered, tech-savvy Muslim career women. Baulch and Pramiyanti (2018), for example, offer relevant discussion of Indonesian women's hijaber's fashionable performances of veiled femininity and subjectivities of chic Muslimah. Across MENA, as in Western contexts, what empowers some women may not benefit others since empowerment is not a one-size-fits all category (Hurley 2021b). Furthermore, 'patriarchy' is not monolithic but refers to the forms of gender domination that are specific to any given context, time, class, ethnicity and sexuality. Patriarchy is thus situated and dependent upon 'the intimate inner workings of culturally and historically distinct arrangements between the genders' (Kandiyoti 1988: 275).

The mashrabiyya framework is important since gender resistance can differ significantly according to scopic regimes. It considers how diverging contexts present women with distinct modes of oppression. Kandiyoti (1988: 275) refers to this as the 'patriarchal bargain'. When considering Arab women learners, the notion of the patriarchal bargain indicates how Arab women might strategise within a set of mashrabiyya constraints, including subtle articulations, performances, invisibilities and silences. Because patriarchy is intersectional, it impacts in varying class, racial, 
secular/non-secular and gendered terms. In the MENA context, the patriarchal bargain can also involve veiled affordances and mashrabiyya practices that are designed to conceal, evade and deflect subjectivities. However, it must again be emphasised that Arab women learners, like the hybridity of mashrabiyya geometric designs, are not monolithic.

Our theoretical framework builds on the body of feminist and visual literature mentioned above. The sense of mashrabiyya represents aesthetics of silence, invisibilities and spaces. It also considers Arab women learners, who might resist the scopic gaze and surveillance of Arab women's bodies; voices and subjectivities (Hurley 2021a; Al-Ali 2021). At the same time, mashrabiyya theoretical mediations align with Ayers (2016: 79) calls to reimagine the 'simple, dark and deep' practices of learning. We therefore develop agile mashrabiyya folds of inquiry.

\section{Folds of Inquiry}

Mashrabiyya feminist postdigital inquiry is a conceptual process for considering social actors' hybrid practices. It is a critically orientated theory of knowledge that seeks to grasp human behaviour through its relationship to technologies, materialisms, matter and the environment. Postdigitalism has been defined in a number of ways (Jandrić et al. 2019), but here we are interested in social actors' fluid postdigital practices (Jandrić 2017).

Mashrabiyya feminist postdigital inquiry thus conceives of liquid spaces (Savin-Baden 2021). This aligns with post-qualitative inquiry's refusal of prescriptive methods, while advocating the risk of developing new theoretical approaches (St. Pierre 2019; Lather 2016). Through the unique conceptual framework of mashrabiyya feminist postdigital inquiry, we hope to explore not only what is seen and voiced but also who and what are silent, invisible, felt, inferred or ignored. This could also reveal some of the normative values of Western scholarship.

To illustrate the scope of the mashrabiyya feminist postdigital framework, we apply it to two examples of practice. The first is an email exchange between a student with the teacher/author. The second is a learners' Twitter icon. The analytic folds of the mashrabiyya feminist postdigital framework are explicit while inquiry considers discreet practices. A summary of these folds is summarised as the following:

- Observable and perceptible elements or mashrabiyya practices at material levels. What can be seen, heard, described and perceived?

- Consideration of mashrabiyya practices' structuring absences. What is silent, invisible, unobservable?

- How do the above mashrabiyya practices come together as a chain of meanings for possible interpretation within the sociocultural context?

- How can mashrabiyya feminist postdigital inquiry address the research questions of the study which ask, (1) How can we conceptualise Arab women students' practices in the postdigital condition? (2) How have Arab women responded to the rapid technological shift to online delivery of education? 
We are also aware that research occurs through the interpretative analytic instrument of the researchers. Next, we say more about our own self-reflexivity informing the narrative.

\section{Self-Reflexivity}

Mashrabiyya feminist postdigital inquiry is sympathetic to autoethnography but differs in important respects. Scopic regimes locate social actors within networks, aesthetics and technologies and lead us to an evolving view of self-reflexivity. We therefore believe that feminist researchers should not avoid the thorny topic of interpretive bias and research could be better informed through self-reflexivity (Bell 2021).

Nevertheless, due to a mashrabiyya perspective we are sensitive to the challenges of displaying positionalities and agree with Hayes (2021) contestation of static principles of inquiry. She questions what notions of equality, diversity and inclusion are based on and whether they can ever be monolithic, fixed and universal. We are also aware of scholars who ask difficult questions about racial positionalities (McArthur 2021).

Mashrabiyya feminist postdigital inquiry considers researchers' perspectives as always informed by intersections of social class, gender, ethnicity, religion, etc. This indicates that you cannot avoid researcher bias. Positionality is fluid, relative and complex but should not merely espouse 'a set of evasions, or settler moves to innocence' (Tuck and Yang 2012: 1). Postdigital researchers can be invisible lurkers offscreen. Nevertheless, it is important to concede that academic researchers are very much creating the narrative of research.

In view of these thorny issues, mashrabiyya feminist postdigital inquiry is not intended to be entirely representational or to impose a fixed version of truth and social reality. Alternatively, it is designed to be theoretically interpretative (Lather 2016; Saint-Pierre 2019). Considering the increasing intersections between offline and online practices, the ability to differentiate between digital and physical spaces is hard to define. What happens online is always informed and embodied by positionality offline (Hurley 2020; Kaur-Gill and Dutta 2017). As mashrabiyya feminist postdigital researchers, we realise these tricky questions of postdigital context as well as the intersections of offline/online sociocultural histories and phenomena.

To address these tensions, the study was informed first, by academic scholarship. Second, previous iterations of feminist postdigital analysis were carried out by both authors (Hurley 2021b; Al-Ali 2021). Third, inquiry was underpinned by recorded critical conversations with 12 Arab women professionals, academics, activists and influencers. However, due to the word limit, theoretical scope of the article and sensitivities surrounding feminism in MENA, we do not refer to these discussions directly and participants' identities are kept anonymous for ethical reasons. Fourth, analytic folds of the interpretive process are explicit and systematic. They are applied to two examples of practice (email and Twitter icon) to illustrate scope of the mashrabiyya feminist postdigital framework. We are also explicit about 
the interpretive subjectivity of the research process (Bell 2021). As the authors of the study, we discuss our positionalities next.

\section{Khadija}

Khadija is a Kuwaiti who currently works at a woman's college in Kuwait with more than 24,000 female students enrolled. She explains that she takes women's issues to heart and seizes every opportunity to understand the young women learners she works with better. Iterations of her research focus on Arab women's silence. In Khadija's 30 years of work, she says that she has witnessed incidents where female students use their silence and voice tactfully and persistently. She interacts with women students who are 'already powerful not in need to be empowered' (Al-Ali 2021).

\section{Zoë}

Originally from the United Kingdom, Zoë is a teacher and postdigital feminist researcher of media and communications at a women's only university in Dubai. Zoë has been in this context for just under a decade while her adult career has been in non-Western contexts, teaching in Malaysia, Brunei, Kuwait and the United Arab Emirates. Zoë's experiences as an international woman academic inform her sensitivity to women's diverse experiences.

Through being members of Lancaster University's Centre for Technology Enhanced Learning, Khadija and Zoë made postdigital contact, via email, to share reflections on teaching at women's only universities in the Gulf during the pandemic. We apply the framework to two postdigital practices, including emails and a Twitter icon. This helps to address the central questions of the study asking, (1) How can we conceptualise Arab women students' practices in the postdigital condition? (2) How have Arab women responded to the rapid technological shift to online delivery of education? In the following two samples of analysis, we use our first names-Khadija and Zoë_-to accent interpretation.

\section{Findings}

\section{Emails of Silence}

The first application of the mashrabiyya feminist postdigital framework is to an email exchange. As mentioned, analytic nodes include, (1) Observable and perceptible elements of the email practices, including material and linguistic features. (2) Consideration of mashrabiyya practices of the emails' structuring absences or what is silent, invisible, unobservable. (3) Exploration of how the email's mashrabiyya practices come together as a chain of meanings for possible interpretation within the sociocultural context. (4) Consideration of how mashrabiyya feminist postdigital interpretation of the emails helps to address the research questions of the study. 
These nodes are applied to a series of email encounters between Khadija and a student who is given the pseudo name of Amal. Khadija has written previously about this email encounter (Al-Ali 2021). In this study, further iterations of analysis occur through the specifically mashrabiyya feminist postdigital inquiry. In this case, the focus is on Khadija's unintentional silences and structural absences within the email exchange. Khadija explains that her silent responses were unintentional because she was offline and unknowingly missed Amal's messages.

First in terms of observable linguistic and material features, Khadija read and printed the emails several times in their original Arabic text. She translated the dialogue into English and was true to the original script by ensuring that English translation was faithful to the original meaning. As mentioned, transcription of this email script has also featured in Khadija's earlier research (Al-Ali, 2021). It is repeated here for further iterations of mashrabiyya feminist postdigital inquiry.

Amal sent her first email which simply read: 'Hello Professor'.

Khadija was silent/absent.

The following day, Amal wrote: 'I am a student in the Tuesday workshop, and I got a B- as my final grade. This grade has really lowered my grade point average (GPA). I was hoping to graduate this year, but my GPA is too low. Can you please raise my grade? I will not be able to graduate with my current GPA and I have already received multiple warnings to raise it.'

Khadija was silent/absent.

Later that day Amal sent another email explaining: 'Professor, I want to graduate this year. It is not fair to have to repeat your module in order to raise my GPA, please help me even if you raise me by one grade.'

Khadija was silent/absent.

Amal next email stated: 'Help me! I have got multiple academic warnings: I will not be able to graduate unless you raise my grade'.

Khadija was silent/absent.

Twenty minutes later Amal emailed, 'Change my grade! It is too low.'

Khadija was silent/absent.

Four hours later she wrote, 'Professor, I am physically and emotionally drained... Please understand what I am going through. I have been trying hard to raise my GPA, but because of the grade you gave me it has dropped.'

Khadija was silent/absent.

One minute later Amal wrote, 'Please, I beg you, raise my grade!'

Khadija was silent/absent.

Amal followed this with sending six crying emojis.

Khadija was silent/absent.

The following day, Amal sent her last email stating: 'Professor, the last day to officially register students' grades is on the $30^{\text {th }}$, so I am begging you; change my grade!'

Khadija was silent/absent.

Amal was silent after the last email.

Second, in terms of mashrabiyya practices' structuring absences and consideration of what is silent, invisible, unobservable, the transcription of the email exchange above makes repeated note of Khadija's (unintentional) silences and 
non-response. Khadija suggests that her unintentional silences triggered Amal's nine textual replies. Silence is revealed as playing a pivotal role in fueling this dynamic engagement. Notably, Amal at no stage questions Khadija's nonresponse and silence thus takes on a dynamical dialogical voice. Following the nineth unanswered email, Amal responded to the silence accordingly.

Third, to address how the above mashrabiyya practices come together as a chain of meanings, for possible interpretation within the sociocultural context, we can observe in the email exchange that Khadija engaged in (unintentional) silent responses to Amal's nine textual emails. Mashrabiyya analysis of the structuring absences, or what is silent, invisible, unobservable, we can identify silence or non-response from Khadija to her student's increasingly urgent emails requesting a grade inflation. Analysis reveals the intersectional range of female practices (D'Ignazio and Klein 2020). Khadija reflects that her silences reveal mashrabiyya dynamics. Khadija says,

Amal did not question my invisible presence; she accepted my silence, understood it and replied accordingly. Between her words and my silence, a dynamic dialogical interaction was revealed. Amal had an obvious goal; to raise her final subject grade, and her task was to convince me to do so. Her first email consisted of a greeting only. Perhaps, Amal hesitated to ask, or wanted to seize my attention, or perhaps, it was a strategy to build her confidence; she initiated the dialogical encounter without a request, and that was received with silence. (Al-Ali 2021)

Here, Khadija theorises the dynamic interplay of silence and voice to suggest that a reductionist dichotomous view of voice/silence must be reorientated. The exchange presents an example of how silence appears differently within mashrabiyya postdigital contexts (hooks 1994; Parpart 2013). Just as mashrabiyya windows disguise and obscure, emails can be sent without reply, but mashrabiyya theorising suggests that-no message-is, simultaneously a strong message in itself. Khadija also argues that silence and voice are dependent on each other. Building on the depiction of silence and voice, Khadija postulates that a dialogically extended mind refers to the integration of individuals' minds into one system in which participants become each other's cognitive extensions. This is accomplished 'through the intersubjective interaction and coordination of the material symbols'-words' (Fusaroli et al. 2014: 6).

Fourth, in relation to addressing the first research question of the study asking, how can we conceptualise Arab women students' practices in the postdigital condition, Khadija says that in this email incident, it is evident that Amal was engaged and part of a dialogical exchange with silence (of a silent/absent tutor) throughout. Silence therefore can be considered both object and subject of the offline/online exchange. Accordingly, Amal constructed a dynamic interaction with silence in each step of the dialogue. Amal is by no means passive victim (Abu-Lughod 2005). She uses email to assert her positionality and pleads to achieve a higher grade. Her perseverance is also quest for empowerment (Baulch and Pramiyanti 2018).

Amal would have contributed her own interpretion of her professor Khadija's silence, what they meant to her and responded accordingly (hooks 1994; Parpart 
2013). These silences_-as subject-object—coordinated her perception and prompted her to share her experience, negotiate her position and further build her argument in terms of an escalating intensity as the email exchange progressed. Khadija says:

...in order to do that Amal had to 'live' in my mind to interpret my silence and engage accordingly and skillfully. In other words, Amal was part of an intersubjective engagement that lead her to experience a composite cognitive unit (Fusaroli et al. 2014). Between my silence and her voice jointly, Amal seemed to be able to apprehend and manipulate what silence meant to her creating 'informational and behavioural interpersonal synergy'. She saw my silence as a collaborative act that allowed building her argument and interacting the way she did. Furthermore, my silence required her collaboration, which is apparent in the entire email episode. My silences were crucial and preceded Amal's leap into building the dialogue, presenting her demands, negotiating the solution the way she did. (Al-Ali 2021)

In response to the second research question, asking how Arab women responded to the rapid technological shift to online delivery of education, application of mashrabiyya feminist postdigital nodes helps to articulate an understanding of the relational, sociocultural and postdigital practices of the emails. The framework structures an articulation of the silence and voice dynamics to reveal the significance of the incident above (hooks 1994; Parpart 2013). We suggest that interpretation is enhanced via the scope of the mashrabiyya feminist postdigital inquiry, since it is explicitly sensitive to offline/online practices of silence. During the Covid-19 online learning regime, several students have been silent and seemingly absent online, which makes it difficult to assess their offline engagement with online learning. Mashrabiyya helps to conceive not only of Amal's pleading but also Khadija's silences in alternate ways (Lorde 1984). Next, the mashrabiyya feminist postdigital framework is applied to consider the veiled affordances of Twitter for masking face via the use of an avatar.

\section{Saving Face on Twitter}

First, Fig. 2 is an example of a student's Twitter icon. The avatar is a black and white image of a women wearing sunglasses and a loose-fitting headscarf. In terms

Fig. 2 Student's Twitter icon

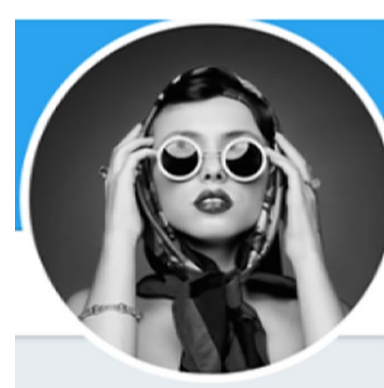

Maryam

Bfashionreaders 1

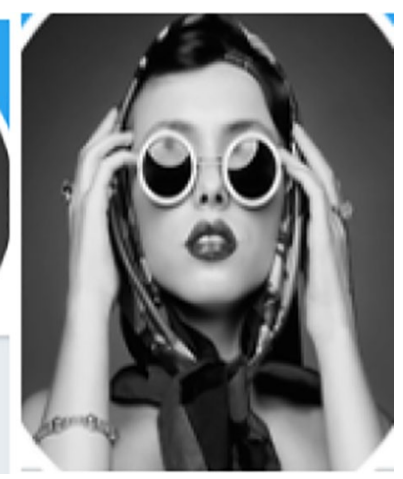


of applying the mashrabiyya feminist postdigital framework, Zoë suggests that we can first consider the observable elements which include the model, colours, iconic portrait, woman wearing retro sunglasses. This portrait is not the student who set up the Twitter account. Rather it is the face of a model that the student has borrowed as icon of her identity on Twitter.

Second, in terms of what is not seen and the structuring absence, the student who created this icon for the Twitter account conceals her own face. She uses a model's face as a mask to represent her subjectivity. To a certain degree, this could be considered a downloadable template or cookie-cutter version of the self, for an instantaneous subjectivity or a McDonaldisation of identity (Hayes 2021).

Third, to consider how the above come together as a chain of meanings for possible interpretation within the sociocultural context, Zoë observes that it is difficult to establish the ethnicity of the avatar or whether she is Arab or Western model. This is because she occupies a visually multicultural stance due to a combination of signifiers or elements: the colour of her skin (white-Caucasian) and headscarf (hijab, Gulf-Arab context).

At the first object level or the meanings to which the image refers, the image is an icon to connote a generically attractive woman framed in a classic 1940s Hollywood style. At a second object level, from the participants' perspective, it shows contemporary Gulf-Arab women's fashions of wearing a hijab (veil) and sunglasses. At the third object level, involving the combination of the first and second objects, the model is not smiling but has a cool, dispassionate expression. The model-avatar looks directly at the viewer, involving them in the image, but due to her sunglasses, we cannot see her eyes. In terms of possible meaning arising from the sociocultural context, Zoë interprets it as an image of glamour but also one of agency and power. The cool, dispassionate expression and sunglasses of the model-avatar indicate the practices of a woman who is in control of her identity, mediating how she is seen and what she sees. Zoë suggests that the sunglasses emphasise her as the subject of the image who is active in the act of looking. Thus, she is not merely an object of another's gaze. The model is touching her sunglasses and the role of her hands within the image indicate that what she wears, how she sees and how she is seen are literally in her own hands. We can add that all those roles could easily be discarded and switched with a touch of her hand, through perhaps removing the sunglasses. Thus, the image both anticipates and deflects the gaze of the viewer.

Fourth, to address the first research question and consider how this icon relates to Arab women's practices in the postdigital condition, the icon of the model is a double object-subject. This emerges through specifically postdigital visual theorising (Pfohl et al. 2021). It suggests the avatar is both classic Hollywood starlet and chic, cosmopolitan Muslimah (Baulch and Pramiyanti 2018). This is not simply a recolonizing mechanism of whiteness but multicultural recombination. The image is Western-Arab and a modern, postdigital Muslimah. Through this icon, she establishes her transnational relevance within a third space (Bhabha 1994). Her third space identity, as simultaneously Arab/Western and postdigital Muslimah, gives her reach as an empowered social actor navigating the global visual economy. All the while, by not showing her face online, she adheres to Arab sociocultural practices of the conservative patriarchal bargain (Kandiyoti 1988). Furthermore, she retains a bit 
of her own offline identity, masking her subjectivities from the glare of surveillance and being under Western eyes (Mohanty 1988).

In response to the second research question, Zoë's application of the feminist postdigital framework reveals mashrabiyya visual practices that the participant develops through her Twitter avatar. It illustrates a high level of self-reflexivity as well as agency of a social actor who takes her postdigital identity into her own hands. Furthermore, Zoë suggests that in terms of non-binary conceptions of postdigital practices, the analysis goes beyond nostalgia for traditional notions of face-to-face practices and pedagogies. This is illustrated quite literally through the substitution of the learners' own face with a model's avatar. We can also consider Belting's (2011a; 2017) extensive analysis of the human face as a social mask. Belting argues that there is an extensive visual, artistic and theatrical history which indicates that the virtual face cannot be reduced to simplistic concealment while the naked face lends itself to mask like practices to conform to social norms. In view of these findings, next, we offer further discussion of our mashrabiyya sense of Arab women learners' postdigital invisibilities, resistance and silences in order to further address the research questions.

\section{Discussion}

The questions of the theoretical study ask, how can we conceptualise Arab women students' practices in the postdigital condition and how have Arab women responded to the rapid technological shift to online delivery of education? The mashrabiyya feminist postdigital framework develops visual inquiry (Pfohl et al. 2021). However, this is not simplistically representational but reflexive of the challenges of interpretation, pixilation and flickers of knowledge. It perceives of Arab women students' practices in postdigital terms, refractive silence and invisibility.

A sense of mashrabiyya postdigital feminist inquiry is important to counter dichotomous theorising. For example, like the Western liberal feminism that has arguably misunderstood, misrepresented, and incorrectly framed Arab women through their analytical and political attempts to 'unveil' and secularise (Ahmed 2011; Eltantawy 2013). Non-secular approaches are considered additional colonialising practices that misappropriate Arab women as passive victim and Other (Ahmed 2011; Mohanty 1988), but forcing Arab women or any social actor to speak or show parts of their bodies which they wish to keep private is intrusive and denies their agency and autonomy (Hurley 2021b). Al-Ali (2021) also discusses how Western feminists have drawn attention to the invisibility of women in literature and academic disciplines; women's experiences are often distorted or misinterpreted. The liberal feminist quest was to correct the record and reveal women's experiences wherever they were absent (Lazreg 1994; Smith 1998). Conversely, Hurley (2021b) suggests that, while some Arab women are culturally discouraged and uninclined to show their faces or bodies online, self-presentations should not be analysed in generic or ethnocentric terms.

The mashrabiyya feminist postdigital inquiry views Arab women students' practices as located within structures of power. However, it departs from Western liberal feminist perspectives which often assume that to posit personal experience as valid is to give women an authoritative voice. Hence, the concepts of experience 
and voice are central to liberal feminist research and thought, although it is difficult to find an agreed definition of the terms. Whether in research or pedagogy, the claim is the same; the validity of experience is fundamental (Weiler 1991). Women as a result are considered empowered when they speak or show their faces and bodies.

In the interpretative analysis above, Khadija emphasises that it is simply erroneous to restrict silence to a reductionist meaning, which evades the complexity and the interrelatedness of silence and voice. In order to understand silence and release other forms of understandings, it must be freed from this dualism. Attention must be drawn to analysing silence, and the different forms it may take (Ellsworth 1989; Lather 1987). Dismantling the binary structure means exploring silence in process and as it is experienced. It also means looking for ways to perceive silence as part of the contextual dynamic and not only as product.

Similarly, Zoë discusses the range of self-presentations, including avatars that Arab women use online while many never show their faces. She explains that social media, like the veil, has certain affordances that enable Arab women to be online while adhering to the contextual patriarchal bargain in the Middle East (Kandiyoti 1988), but within online settings, and according to liberal feminist research in particular, the dichotomy of voice and silence is pervasive, as is the decision of whether or not to show face online.

Al-Ali contends that silence is considered passive within computer-mediated communication and there is an inherent bias against silence within online communication. Liberal feminist online theorising also seems biased and based on the preference of voice over silence, showing face and being seen as an assertion of women's agency, authority and presence. However, this is an argument that extends from a face-to-face conception of learning. It also stems from Western notions of identity and impression management, but Belting (2017) emphasises that while the face plays a critical role in human communication, it defies simplistic or universal definition. Belting discusses faces as masks of the self and portraiture as a constantly evolving mask in Western culture, as well as the changing fate of the face in the age of new media.

Conversely, mashrabiyya feminist postdigital inquiry appreciates how self-presentations by Arab women occur within confined parameters while revealing how they could vary. At the same time, considering the cache of visibility, it is important to appreciate how Arab women's faces and appearance are often scrutinized, censored and subject to varying consequences within the patriarchal bargain (Kandiyoti 1988). Furthermore, Arab women's bodies have become a battlefield of signs surrounding intersections of patriarchy, postcolonialism, capitalism, traditionalism and Islam (Odeh 1993).

While a minority of our students in Kuwait and Dubai universities wears the niqab (facial veil) in public, the majority do not show their faces during online classes. Importantly, learning during Covid-19 often took place in crowded homes, while women are taking care of their children or siblings. Home learning resulted in many women's increase of responsibilities, multitasking home and careers. Other negative consequences include domestic violence, divorce and substance abuse. Consequently, it is no surprise that Covid-19 is claimed to have set gender equality back by more than two decades (Lungumbu and Butterly 2020). Moreover, turning on cameras and microphones is potentially intrusive and embarrassing in the 
domestic sphere. Therefore, mashrabiyya invisibilities and/or silence prove to be liberating and convenient practices for some learners. This inquiry leads us to the important realisation of the anchoring of a solid boundary between the private and the public; not entirely due to gendered customs and inappropriateness of showing Arab female faces (online), as Hurley (2021a) initially suggests, but as a tactic intended to shield the private life from the gaze of others (females and males).

We therefore consider mashrabiyya practices, not entirely as deficit, but, as subtle resistance and navigation of gendered difficulties (Parpart 2013). Silence/invisibility is also a means to navigate the pragmatic patriarchal bargain (Kandiyoti 1988). Mashrabiyya bargaining facilitates Arab women learners with refractive online positionalities that cannot always be seen or heard. This is a form of bargaining since it complies with patriarchal traditions of backgrounding women while simultaneously enabling them to dodge the intrusive surveillance of online scopic regimes. Arab women learners are not necessarily subjects relying on a master's tools (Lorde 1984). Neither are they subservient to Western liberal feminist conceptions of visible and vocal liberation (Baulch and Pramiyanti 2018). Alternatively, mashrabiyya inquiry problematises universalised conceptions of gender empowerment. It also contests forcible unveiling, demasking and obligations for Arab women learners to show face online or to speak when they opt for silence. Next, we offer some conclusions, limitations and recommendations for future research.

\section{Conclusion}

Mashrabiyya feminist postdigital inquiry is developed as an interpretive theoretical framework. It conceptualises Arab women students' practices in the postdigital condition and how Arab women have responded to the rapid technological shift to online delivery of education. Importantly, it extends visual theorising (Mirzoeff 2006; Pfohl et al. 2021). Inquiry into scopic regimes builds on the spirit of earlier feminisms, such as the pragmatism of Jane Addams or Julia Haywood Cooper and salvaging of Seigfried (1996). It contributes to the radical feminist initiatives of theorists like Lorde (1984), St. Pierre (2019) and Lather (2016), who have struggled to assemble new feminist vocabularies and theoretical tools. It aligns with hooks' (1994) and Parpart's (2013) suggestions that we could come to know differently through fragments and spaces of silence. Through reference to Arab feminist literature, it suggests that silence, invisibility and/or pleading are not necessarily passive (Ahmed 2011; Eltantawy 2013).

Simultaneously, the study does not deny that Arab women learners, like Amal in Khadija's study, can be loud, visible have or a striking online presence (Hurley $2019 \mathrm{a}, \mathrm{b})$, but it is attuned to contextual practices of the patriarchal bargain that Arab women mediate (Kandiyoti 1988). Moreover, Arab women's relative resistance, of silence and invisibilities, like Zoë's student use of the Twitter avatar, are entangled within intersectional practices. This indicates non-Western subjects who do not necessarily have a European Enlightenment perspective of voice, visibility or direct emancipation. 
Similarly, through our mashrabiyya theorising, we realise the gaps in Western scholarship surrounding social actors' diverse ontologies and epistemologies. We thus suggest Eurocentric and androcentric conceptional frameworks are limited, weary, depleted. The contribution of this study is the agility of mashrabiyya. This views learners' practices, often occurring below the radar, within and beyond pixilation of mashrabiyya screens.

Limitations of the article are that it ironically does not provide space for Arab women students to be directly voiced or represented. However, it appreciates Arab women learners' refractive postdigital practices. This aligns with post-qualitative theorising that ruptures the hegemony of Eurocentric and androcentric scholarship (Lather 2016; St. Pierre 2019). The mashrabiyya feminist postdigital framework could also be generalisable to other research agendas informed by social actors' discreet onto-epistemologies. It is recommended that future studies consider, not only what learners and educators can show and say but, also, blank spaces, silences and deflections. This includes practices below the radar, behind, beyond and within the bridges of the postdigital screen (Abidin 2021).

Finally, within the neoliberal ruins of the pandemic university, we walk amongst conceptual remnants of the liberal humanist subject. Consequently, although we might like to cast off cultural baggage, to pass through the Covid-19 portal in a light, breezy yet combative manner, suggested by Roy (2020), gendered practices are not necessarily disposable, but new theoretical tools, of mashrabiyya inquiry, refuse essentialist narratives of scopic regimes. Inquiry contests universalised notions of learners and educators. Furthermore, just as many of us are now wearing face masks due to the pandemic, we might reflect that the face has always been a filter that is disciplined according to social subjectivities. Perhaps Arab women learners have other insights into refractive practices of veils, silences and mashrabiyya to evade hegemony. Pragmatic evasion — as tangible object—could be pertinent for shielding from the glare of surveillance capitalism. Silence, invisibility, being offline or disconnected are thus refractive resistance to technological tethering.

\section{References}

Abed, G., \& Davoodi, H. (2003). Challenges of Growth and Globalization in the Middle East and North Africa. International Monetary Fund. https://www.imf.org/external/pubs/ft/med/2003/eng/abed.htm. Accessed 26 June 2021.

Abidin, C. (2021). From "Networked Publics" to "Refracted Publics": A Companion Framework for Researching "Below the Radar" Studies. Social Media + Society, 7(1), 205630512098445. https:// doi.org/10.1177/2056305120984458

Abu-Lughod, L. (2005). Dialects of Women's Empowerment: The International Circuitry of the Arab Human Development Report 2005. International Journal of Middle East Studies, 41(1), 103a. https://doi. org/10.1017/s0020743808090521

Ahmed, L. (2011). A Quiet Revolution: The Veil's Resurgence, From the Middle East to America. New Haven, CN: Yale University Press.

Al-Ali, K. (2021). 'Silence', the Invisible Tool of a Dialogically Extended Mind: An Email Experience of a Kuwaiti Tutor in Higher Education. Studies in Technology Enhanced Learning. https://doi.org/10. $21428 / 8 \mathrm{c} 225 \mathrm{f} 6 \mathrm{e} .514 \mathrm{~b} 8258$

Al-Fassi, H. (2007). Women in Pre-Islamic Arabia. Oxford: British Archaeological Reports (BAR) Archaeopress. 
Anderson, G. (2020). Students say online classes aren't what they paid for. Inside Higher Ed, 13 April. https://www.insidehighered.com/news/2020/04/13/students-say-online-classes-arent-what-theypaid.. Accessed 26 June 2021.

Ayers, W. (2016). Teaching With Conscience in an Imperfect World. New York: Teachers College Press.

Badran, M., \& Cooke, M. (2004). Opening the Fates. Bloomington, IN: Indiana University Press.

Baulch, E., \& Pramiyanti, A. (2018). Hijabers on Instagram: Using Visual Social Media to Construct the Ideal Muslim Woman. Social Media + Society, 4, 1-15. https://doi.org/10.2139/ssrn.3353158

Bell, L. (2021). Ethics and Feminist Research. In S. Hess-Biber, Feminist Research Practice: A Primer (pp. 73-106). Los Angeles: SAGE.

Belting, H. (2011a). An Anthology of Images. Princeton, NJ: Princeton University Press.

Belting, H. (2011b). Florence \& Baghdad: Renaissance Art and Arab Science. Cambridge, MA: Harvard University.

Belting, H. (2017). Face and Mask: A Double History. Princeton, NJ: Princeton University Press.

Bhabha, H. (1994). The Location of Culture. London: Routledge.

Brown, W. (2015). Undoing the Demos. Neoliberalism's Stealth Revolution. New York: Zone Books.

D'Ignazio, C., \& Klein, L. (2020). Data Feminism. Cambridge, MA: MIT Press.

El Saadawi, N. (1983). Memoirs from the Women's Prison. London: Zed Books.

Ellsworth, E. (1989). Why Doesn't This Feel Empowering? Working through the Repressive Myths of Critical Pedagogy. In C. Luke \& J. Gore, Feminisms and Critical Pedagogy (pp. 90-119). London: Routledge.

Eltantawy, N. (2013). From Veiling to Blogging: Women and media in the Middle East. Feminist Media Studies, 13(5), 765-769. https://doi.org/10.1080/14680777.2013.838356

El-Tohamy, A. (2021). Palestine's Education Institutions Are Victims of Conflict Again. Al-Fanar Media, 18 May. https://www.al-fanarmedia.org/2021/05/palestines-education-institutions-are-victims-ofconflict-again/. Accessed 26 June 2021.

Fusaroli, R., Gangopadhyay, N., \& Tylén, K. (2014). The dialogically extended mind: Language as skilful intersubjective engagement. Cognitive Systems Research, 29-30, 31-39. https://doi.org/10.1016/j. cogsys.2013.06.002

Giroux, H. (2004). Public Pedagogy and the Politics of Neo-Liberalism: Making the Political More Pedagogical. Policy Futures In Education, 2(3-4), 494-503. https://doi.org/10.2304/pfie.2004.2.3.5

Grewal, I., \& Kaplan, C. (2006). Scattered hegemonies. Minneapolis, MN: University of Minnesota Press.

Hayes, S. (2021). The Value of Postdigital Humans as Objects, or Subjects, in McDonaldised Society. In M. Savin-Baden (Ed.), Postdigital Humans: Transitions, Transformations and Transcendence (pp. 71 - 88). Cham: Springer. https://doi.org/10.1007/978-3-030-65592-1_5

hooks, b. (1994). Teaching to Transgress. New York: Routledge.

Hurley, Z. (2019a). Imagined Affordances of Instagram and the Fantastical Authenticity of Gulf-Arab Social Media Influencers. Social Media + Society, 5 (1). https://doi.org/10.1177/2056305118819241

Hurley, Z. (2019b). Why I No Longer Believe Social Media is Cool . . Social Media + Society, 5(3), 205630511984949. https://doi.org/10.1177/2056305119849495

Hurley, Z. (2020). Postdigital Feminism and Cultural Visual Regimes: Covid-19 at Women's Only University in the Gulf. Postdigital Science And Education, 2(3), 645-650. https://doi.org/10.1007/ s42438-020-00134-3

Hurley, Z. (2021a). Dialogic theorising of Emirati women's technology enhanced learning in the United Arab Emirates. Studies In Technology Enhanced Learning. https://doi.org/10.21428/8c225f6e. b70d4b5a

Hurley, Z. (2021b). \#reimagining Arab Women's Social Media Empowerment and the Postdigital Condition. Social Media + Society, 7(2), 205630512110101. https://doi.org/10.1177/20563051211010169

Education International (2021). Higher Education Privatisation and Commercialisation. https://issuu. com/educationinternational/docs/2021_eiresearch_gr_covid19_commercialisation_digit/s/ 11667194. Accessed 26 June 2021.

Jandrić, P. (2017). Learning in the Age of Digital Reason. Rotterdam: Sense.

Jandrić, P., Ryberg, T., Knox, J., Lacković, N., Hayes, S., \& Suoranta, J. et al. (2019). Postdigital Dialogue. Postdigital Science And Education, 1(1), 163-189. https://doi.org/10.1007/s42438-018-0011-X

Jay, M. (1988). Scopic Regimes of Modernity. In H. Foster, Vision and Visuality. Seattle: Seattle Bay Press.

Johnston, I. (2021). UK risks 'turning clock back' on gender equality in pandemic. Guardian, 9 February. https://www.theguardian.com/lifeandstyle/2021/feb/09/uk-risks-turning-clock-back-on-genderequality-in-pandemic. Accessed 26 June 2021. 
Jolly, J. (2021). 'It's just the beginning': Covid push to digital boosts big tech profits. Guardian, 1 May. https://www.theguardian.com/business/2021/may/01/its-just-the-beginning-covid-push-to-digitalboosts-big-tech-profits. Accessed 26 June 2021.

Kandiyoti, D. (1988). Bargaining with Patriarchy. Gender \& Society, 2(3), 274-290. https://doi.org/10. $1177 / 089124388002003004$.

Kaur-Gill, S., \& Dutta, M. (2017). Digital Ethnography. In J. Matthes (Ed.), The International Encyclopedia of Communication Research Methods. Wiley-Blackwell. https://doi.org/10.1002/9781118901731. iecrm0271.

Lather, P. (1987). Feminist Perspectives on Empowering Research Methodologies. Women's Studies International Forum, 11(6), 569-581. https://doi.org/10.1016/0277-5395(88)90110-0.

Lather, P. (2016). Top Ten+ List. Cultural Studies $\leftrightarrow$ Critical Methodologies, 16(2), 125-131. https:// doi.org/10.1177/1532708616634734.

Lazreg, M. (1994). Women's Experience and Feminist Epistemology: A critical neo-rationalist approach. In K. Lennon \& M. Whitford (Eds.), Knowing the Difference (pp. 59-76). London: Routledge.

Lightfoot, M. (2016). Education Technology Policies in the Middle East. Cham: Palgrave Macmillan.

Lorde, A. (1984). Sister Outsider: Essays and speeches. Toronto: Crossing Press.

Lungumbu, S., \& Butterly, A. (2020). Coronavirus and gender: More chores for women set back gains in equality. BBC, 26 November. https://www.bbc.com/news/world-55016842. Accessed 26 June 2021.

McArthur, J. (2021). Critical Theory in a Decolonial Age. Educational Philosophy and Theory. https:// doi.org/10.1080/00131857.2021.1934670.

Metz, C. (1975). The Imaginary Signifier. Screen, 16(2), 14-76. https://doi.org/10.1093/screen/16.2.14.

Metz, C. (1982). The Imaginary Signifier. Bloomington, IN: Indiana University Press.

Mirzoeff, N. (2006). On visuality. Journal of Visual Culture, 5(1), 53-79. https://doi.org/10.1177/ 1470412906062285.

Mohanty, C. (1988). Under Western Eyes: Feminist Scholarship and Colonial Discourses. Feminist Review, 30, 61. https://doi.org/10.2307/1395054.

Mwai, P. (2021). Covid-19 vaccines: Why some African states can't use their vaccines. BBC, 8 June. https://www.bbc.com/news/56940657. Accessed 26 June 2021.

Odeh, L. (1993). Post-Colonial Feminism and the Veil: Thinking the Difference. Feminist Review, 43, 26-37. https://doi.org/10.2307/1395067.

O'Keefe, F. (2014). Modern mashrabiya is Arab architecture made in the shade - check out these stunning photos - Green Prophet. https://www.greenprophet.com/2014/06/modern-mashrabiya-is-arabarchitecture-made-in-the-shade/. Accessed 26 June 2021.

Parpart, J. (2013). Choosing Silence: Rethinking voice, agency and women's empowerment. In R. RyanFlood \& R. Gill (Eds.), Secrecy and Silence in the Research Process (pp. 34-48). Oxfordshire: Routledge.

Pfohl, S., Ayes, B., Turner, A., Amoo-Adare, E., Zecchin, M., \& Borowski, M. et al. (2021). Simple, Dark, and Deep: Photographic Theorizations of As-Yet Schools. Postdigital Science And Education. https://doi.org/10.1007/s42438-021-00233-9.

Roy, A. (2020). The pandemic is a portal. Financial Times, 3 April. https://www.ft.com/content/10d8f 5e8-74eb-11ea-95fefcd274e920ca. Accessed 26 June 2021.

Savin-Baden., M. (2021). Postdigital Humans: Transitions, Transformations and Transcendence. Cham: Springer.

Sawahel, W. (2021). Universities, schools close in the wake of COVID-19 surge. University World News, 23 May. https://www.universityworldnews.com/post.php?story=20210523181129950. Accessed 26 June 2021.

Seigfried, C.H. (1996) Pragmatism and Feminism: Reweaving the Social Fabric. Chicago. Chicago University Press.

Smith, D. (1998). The Everyday World as Problematic. Milton Keynes: The Open University Press.

St. Pierre, E. (2019). Post Qualitative Inquiry, the Refusal of Method, and the Risk of the New. Qualitative Inquiry, $107780041986300 \mathrm{https} / / /$ doi.org/10.1177/1077800419863005.

Suri, C. (2017). Jean Nouvel Reveals His Singular Vision Behind the Louvre Abu Dhabi. Architecture Digest, 7 November. https://www.architecturaldigest.com/story/jean-nouvel-louvre-abu-dhabi. Accessed 26 June 2021.

Taylor, A. (2017). The Opening of the Louvre Abu Dhabi. The Atlantic, 8 November. https://www. theatlantic.com/photo/2017/11/the-opening-of-the-louvre-abu-dhabi/545333/. Accessed 26 June 2021.

Tijani, I. (2009). Male Domination, Female Revolt. Leiden: Brill. 
Tuck, E., \& Yang, K. (2012). Decolonization is not a Metaphor. Decolonization: Indigeneity, Education \& Society, 1(1), 1-40.

Watt, W. (1994). Islamic Creeds. Edinburgh: Edinburgh University Press.

Weiler, K. (1991). Freire and a Feminist Pedagogy of Difference. Harvard Educational Review, 61(4), 449-475. https://doi.org/10.17763/haer.61.4.a102265j168rju84 